\title{
Development and Characterization of a Combination Tablet Dosage Form Containing Sofosbuvir and Ribavirin Using Design of Experiments (DoE) Approach
}

\author{
Md. Anisul Islam, Md. Mahbubul Alam, K. M. Yasif Kayes Sikdar, \\ A. S. M. Monjur-Al-Hossain and Abu Shara Shamsur Rouf \\ Department of Pharmaceutical Technology, Faculty of Pharmacy, University of Dhaka, \\ Dhaka-1000, Bangladesh
}

(Received: March 31, 2021; Accepted: June 09, 2021; Published (web): June 20, 2021)

\begin{abstract}
Worldwide more than 180 million people get infected by chronic Hepatitis C Virus (HCV) and around 700,000 people pass away every year due to HCV related problems. Sofosbuvir and Ribavirin are prescribed as combined medication for the management of HCV infection globally. Therefore, optimization of a pharmaceutical dosage form containing Sofosbuvir and Ribavirin can open a new hope in the treatment of HCV infection. This study was conducted by using the Design of Experiments (DoE) approach. It is a systematic process aiming to determine the correlation between formulation factors affecting the approach and the output of the approach. During the development of formulations, two factors were considered, which are Croscarmellose Sodium (CCS) and Povidone $\mathrm{K} 30$ (PK30) at different concentrations ranging from $0.19 \%$ to $2.31 \%$ of the total tablet weight in 9 different formulations. Their effect on disintegration time (DT) was evaluated through statistical method and it was found between $3 \pm 0.003$ and $6.5 \pm 0.015$ minutes. The use of these two different disintegrants exhibited a significant effect on DT. The contour plot showed predicted ranges of concentrations of CCS and PK30 for desired DT. Fourier Transform Infrared Spectroscopy (FTIR) data, Thermogravimetric Analysis (TGA) and X-ray Diffractometry (XRD) spectrums confirmed that there was no interaction between Sofosbuvir and Ribavirin or with any other excipients used in this experiment.
\end{abstract}

Key words: Sofosbuvir, Ribavirin, Hepatitis C Virus (HCV), Design of Experiments (DoE)

\section{INTRODUCTION}

Hepatitis C, a positive single-stranded RNA virus, affects 170 million people worldwide. ${ }^{1}$ The prevalence of Hepatitis C Virus (HCV) related infection is estimated at 2 to $3 \%$ globally. ${ }^{2-3}$ Each year approximately 700,000 persons expire due to medical complications created by HCV. ${ }^{4}$ Hepatitis C is considered an important cause of chronic liver disease. ${ }^{5}$ Till now no consensus treatment option for Hepatitis $\mathrm{C}$ is available worldwide. Therefore, the management of $\mathrm{HCV}$ infection is a challenge for prescribers.

Correspondence to: Abu Shara Shamsur Rouf Email: rouf321@yahoo.com

Dhaka Univ. J. Pharm. Sci. 20(1): 121-133, 2021 (June) DOI: https://doi.org/10.3329/dujps.v20i1.54040
Sofosbuvir and Ribavirin are widely used for the management of Hepatitis C. ${ }^{6}$ Clinical trials have shown that Ribavirin alone can normalize W201 alanine aminotransferase levels during treatment but it could not reduce the level of HCV RNA during or even after therapy, so it was imminent that alone it could not produce any sustained antiviral response. ${ }^{7}$ Sofosbuvir is a direct-acting antiviral drug that affects HCV. However, it is not effective if taken alone and leads to drug resistance. ${ }^{8}$ So, it is recommended to take Sofosbuvir with another directacting antiviral drug like Ribavirin.

Sofosbuvir is a white to off-white crystalline solid having chemical formula $\mathrm{C}_{22} \mathrm{H}_{29} \mathrm{FN}_{3} \mathrm{O}_{9} \mathrm{P}$ and molecular weight $529.45 \mathrm{~g} / \mathrm{mol}$ with moderate solubility in water and melting point $120-125{ }^{\circ} \mathrm{C}$. 
While, Ribavirin is a white to off-white crystalline powder having chemical formula $\mathrm{C}_{8} \mathrm{H}_{12} \mathrm{~N}_{4} \mathrm{O}_{5}$ and molecular weight $244.2 \mathrm{~g} / \mathrm{mol}$. It is freely soluble in water and slightly soluble in anhydrous alcohol with a melting point of $174-176{ }^{\circ} \mathrm{C} .{ }^{10}$

The design of experiments (DoE) aims to define the connection between affecting factors and the outputs of those factors on a process. ${ }^{11}$ In the DoE approach, controlled input factors are systematically varied to determine their effects on output responses. It allows determining the most important input factors correlating their optimized output responses and ultimately the illustration of interactions between those input factors. ${ }^{12}$ So, the primary objective of this study was to develop a tablet dosage form containing Sofosbuvir and Ribavirin in combination via the application of statistical approach named Design of experiments (DoE).

\section{MATERIALS AND METHODS}

Chemicals and reagents. Sofosbuvir and Ribavirin drug substances were dispensed as an openhanded contribution by Incepta Pharmaceuticals Limited, Bangladesh. Stock solutions were prepared using those supplied drug substances and these solutions were used for comparative studies and for preparing standard curve. Super disintegrant and diluent named Croscarmellose Sodium and
Microcrystalline Cellulose respectively were purchased from Colorcon Asia Pvt. Ltd, India. Colloidal Silicon Dioxide, Povidone K30 and Magnesium Stearate respectively were collected from the Pharmaceutics research lab, University of Dhaka, Bangladesh. Deionized water was supplied by a water purifier system (Millipore Milli-Q from Bedford, MA, USA).

Formulation design. In the DoE approach, variables are the factors that can be changed accordingly to get our desired response and response is the measurement of the outcome while variables are the measure of control. In our study, two variables and a response were considered while designing a series of formulations, to be optimized by the DoE method. The variables were Croscarmellose Sodium (X1) and Povidone K30 (X2) while the response was disintegration Time (Y). Considering these variables, 9 formulations were developed by the Design of Experiments (DoE) method through Minitab 17 software (Minitab, LLC, Pennsylvania, USA). In the software, the values of variables were measured in percentage with the highest and lowest percentage of $0.19 \%$ and $2.31 \%$ respectively. Software generated amounts of two variables and the overall formulation of 9 different batches are shown in table 1.

Table 1. Formulations of immediate-release tablets containing Sofosbuvir and Ribavirin including Minitab 17 generated percentage amount of two variables in different batches.

\begin{tabular}{lcccccccccc}
\hline $\begin{array}{l}\text { Batch } \\
\text { No. }\end{array}$ & $\begin{array}{c}\text { Sofosbuvir } \\
\mathrm{mg}\end{array}$ & $\begin{array}{c}\text { Ribavirin } \\
\mathrm{mg}\end{array}$ & \multicolumn{2}{c}{$\mathrm{CCS}(\mathrm{X} 1)$} & \multicolumn{2}{c}{ PK30 (X2) } & MCC & $\begin{array}{c}\text { CSD } \\
\mathrm{mg}\end{array}$ & $\begin{array}{c}\text { MS } \\
\mathrm{mg}\end{array}$ & $\begin{array}{c}\text { Total } \\
\mathrm{mg}\end{array}$ \\
\hline 1 & 400 & 200 & 10 & $1.25 \%$ & 18.48 & $2.31 \%$ & 163.52 & 4 & 4 & 800 \\
2 & 400 & 200 & 16 & $2.00 \%$ & 16 & $2.00 \%$ & 160 & 4 & 4 & 800 \\
3 & 400 & 200 & 10 & $1.25 \%$ & 1.52 & $0.19 \%$ & 180.48 & 4 & 4 & 800 \\
4 & 400 & 200 & 16 & $2.00 \%$ & 4 & $0.50 \%$ & 172 & 4 & 4 & 800 \\
5 & 400 & 200 & 1.52 & $0.19 \%$ & 10 & $1.25 \%$ & 180.48 & 4 & 4 & 800 \\
6 & 400 & 200 & 18.48 & $2.31 \%$ & 10 & $1.25 \%$ & 163.52 & 4 & 4 & 800 \\
7 & 400 & 200 & 4 & $0.50 \%$ & 4 & $0.50 \%$ & 184 & 4 & 4 & 800 \\
8 & 400 & 200 & 10 & $1.25 \%$ & 10 & $1.25 \%$ & 172 & 4 & 4 & 800 \\
9 & 400 & 200 & 4 & $0.50 \%$ & 16 & $2.00 \%$ & 172 & 4 & 4 & 800 \\
\hline
\end{tabular}

Here, $\mathrm{CCS}=$ Croscarmellose Sodium; PK30= Povidone K30; MCC $=$ Microcrystalline Cellulose; $\mathrm{CSD}=$ Colloidal Silicon Dioxide; MS= Magnesium Stearate. 
Formulation of immediate-release tablets. The direct compression method was used to prepare immediate-release tablets. Initially, excipients were passed through mesh screen number 30 (Yuyao Haiju Lab Equip. Co. Ltd, China) and were weighed accurately for 50 tablets using electronic weighing balance before starting the compression process. All excipients except magnesium stearate were mixed through proper trituration for 30 minutes in mortar and pestle. Previously sieved and accurately weighed amount of magnesium stearate was then added and mixing was done again for another 10 minutes. After weighing and mixing tests were done to evaluate the powder mixture followed by compression.

Pre-compression evaluation of powder blends. After mixing the ingredients and before compression several tests were done to evaluate the powder blends named bulk density, tapped density, Carr's index, Hausner's ratio and angle of repose.

Bulk density. It was measured by pouring a powder into a $10 \mathrm{ml}$ measuring cylinder and initial weight of powder was noted. This initial volume is called the bulk volume. Bulk density can be calculated according to the formula mentioned below ${ }^{13}$ -

$$
\mathbf{D}_{\mathrm{b}}=\mathbf{M} / \mathbf{V}_{\mathbf{b}}
$$

Here, $D_{b}=$ Bulk density $(\mathrm{gm} / \mathrm{ml}), M=$ Mass of powder $(\mathrm{gm}), \mathrm{V}_{\mathrm{b}}=$ Bulk volume of the powder $(\mathrm{ml})$

Tapped density. After measuring the bulk density the powder was tapped for 500 times by Powder Tapped and Bulk Density Tester (Electrolab, India) and the volume was noted. Then the powder was tapped for additional 750 times and again the new volume was noted. The later volume was considered as tapped volume. Tapped density can be calculated according to the formula mentioned below ${ }^{13}$ -

$$
D_{t}=M / V_{t}
$$

Here, $D_{\mathrm{t}}=$ Tapped Density $(\mathrm{gm} / \mathrm{ml}), \mathrm{M}=$ Mass of powder $(\mathrm{gm}), \mathrm{V}_{\mathrm{b}}=$ Tapped volume of the powder $(\mathrm{ml})$

Carr's index. Carr's index was measured by using bulk density and tapped density by the following formula ${ }^{14}$ -

$$
\text { Carr's Index }=\left\{\left(D_{b}-D_{t}\right) / D_{b}\right\} \times 100
$$

Hausner's ratio. Hausner's ratio was calculated by the following formula ${ }^{14}$ -

Hausner's ratio $=D_{t} / D_{b}$

Angle of repose. Angle of repose was determined using fixed funnel method. The powder blend was poured through a funnel that can be raised vertically until a maximum cone height (h) was obtained. Radius of the heap (r) was measured carefully. Angle of repose was calculated using following formula ${ }^{14}$ -

$$
\theta=\tan ^{-1}(\mathbf{h} / \mathbf{r})
$$

Here, $\theta=$ Angle of repose, $h=$ Height of pile, $r=$ Radius of the base pile.

Tablet compression. After the evaluation of the powder blends, the compression process was done by using a rotary tablet machine (ZP-17 E Rotary Tablet Press Machine, Shanghai Pharmaceutical Machinery Co. Ltd., China). The specifications of the compression machine were same for all nine formulations. Before compression, the tablet machine, the punches and the die cavities were cleaned carefully. The cleaning process was done before and after of compression of every batch. The compressed tablets were in caplet shape and white in color and no coating was done after the compression.

Compressed tablets evaluation. After compression, the tablets were stored in an airtight container. To evaluate the tablets- tablet hardness, length, width and diameter, friability, uniformity of weight, disintegration time and dissolution test were performed.

Tablet hardness. Hardness of 6 tablets of each batch were determined by calculating the force required to crush the tablets using Automatic Tablet Hardness Tester (Unitech, New Delhi, India). ${ }^{15}$

Tablet length, width and diameter. These measurements were done by placing tablets between two arms of the slide calipers. Six tablets of each batch were measured for each parameter.

Friability. Roche friabilator (Electrolab, New Delhi, India) was used for this test. 10 tablets of each batch were weighed accurately and placed in the 
tumbling apparatus that revolved at $25 \mathrm{rpm}$ dropping the tablets through a distance of six inches with each revolution. After $4 \mathrm{~min}$, the tablets were weighed and the percentage loss in tablet weight was determined and friability was measured by the following equitation ${ }^{16}$ -

\section{Friability $=\left[\left(\mathrm{W}_{\mathrm{i}}-\mathrm{W}_{\mathrm{f}}\right) / \mathrm{W}_{\mathrm{i}}\right] \times \mathbf{1 0 0}$}

Here, $\mathrm{W}_{\mathrm{i}}=$ Initial weight of tablets, $\mathrm{W}_{\mathrm{f}}=$ Final weight of tablets

Uniformity of weight. Individual weights of 10 tablets from each batch were weighed accurately using an Electronic Balance to calculate uniformity of weight following the United States Pharmacopeia (USP) guideline. ${ }^{17}$

Disintegration time. This test was performed in Basket-Rack Assembly method by Disintegration Tester (Erweka, Germany). $1000 \mathrm{ml} \quad 0.1 \quad \mathrm{~N}$ Hydrochloric Acid $(\mathrm{HCl})$ in aqueous medium was used as disintegration media and the temperature was set at $37{ }^{\circ} \mathrm{C}$. 6 tablets for each batch were placed in individual baskets and the machine was set at 30 cycles per minute. The time required to disintegrate the tablets were measured carefully. ${ }^{18}$

Standard curve preparation of Sofosbuvir and Ribavirin. $10 \mathrm{mg}$ Sofosbuvir powder was weighed by electronic balance. This powder was taken in a $100 \mathrm{ml}$ volumetric flask and filled with 0.1 $\mathrm{N} \mathrm{HCl}$ up to the mark. The flask was shaken well until the Sofosbuvir powder was dissolved. 8 test tubes were taken and marked serially from 1-8 and were kept in a test tube holder. 8 different solutions of different concentrations such as 5, 10, 15, 20, 25, $30,35,40 \mu \mathrm{g} / \mathrm{mL}$ were made by serial dilution. Absorbance of all the diluted solutions were measured by UV-Visible Scanning Spectrophotometer, UV-1800 (Shimadzu, Kyoto, Japan) at $261 \mathrm{~nm}$. Standard curve of Sofosbuvir was prepared by using those absorbance vs concentration value with Microsoft Excel (Microsoft Corporation, Washington, USA). The standard curve of Ribavirin was prepared following the same procedure where absorbance was measured at $207 \mathrm{~nm}$.

Dissolution study. Drug release study was performed for all formulations using USP type-II dissolution apparatus (Erweka, Germany). $900 \mathrm{ml}$ of $0.1 \mathrm{~N} \mathrm{HCl}$ at $37{ }^{\circ} \mathrm{C}$ temperature was used as dissolution media. 6 tablets of each batch were placed in individual media containing beaker and stirred at $50 \mathrm{rpm}$ (revolution per minute). Five milliliters of aliquots were periodically withdrawn in every 5 minutes interval and the sample volume was replaced with an equal volume of fresh dissolution media. The samples were analyzed spectrophotometrically at 261 $\mathrm{nm}$ and $207 \mathrm{~nm}$ by UV-Visible Scanning Spectrophotometer. The results were compared with the standard curves of Sofosbuvir and Ribavirin and $\%$ drug release were calculated. ${ }^{19}$

Drug-drug and drug-excipients compatibility study. Fourier Transform Infrared (FTIR) spectroscopy analysis, Thermogravimetric analysis (TGA), X-ray Diffraction (XRD) analysis and Scanning Electron Microscopy (SEM) analysis were performed to evaluate drug-drug and drug-excipients compatibility.

Fourier transform infrared (FTIR) spectroscopic analysis. Sofosbuvir powder, Ribavirin powder, physical mixture of all Active Pharmaceutical Ingredients (API) and excipients, crushed powder of compressed tablets were subjected to FTIR analysis (FTIR Spectrum Two ${ }^{\mathrm{TM}}$ L160000T of Perkin Elmer, USA) to identify any interaction between drugs and excipients.

Thermogravimetric analysis (TGA). TGA was performed on Sofosbuvir powder, Ribavirin powder, Sofosbuvir and Ribavirin powder mixture and crushed powder of compressed tablet by Thermogravimetric Analyzer TGA-50H (Mettler Toledo, Switzerland) to determine the individual thermal stability of these samples.

X-ray diffraction (XRD) analysis. Crystalline nature of Sofosbuvir powder, Ribavirin powder, Sofosbuvir and Ribavirin powder mixture and crushed powder of compressed tablet and extent of its conversion to amorphous form were studied by X-ray Diffractometer XRD-6100 (Shimadzu, Japan).

Scanning electron microscopy (SEM). SEM analysis of chysical mixture powder of all APIs and excipients (500X magnification), tablet surface 
(500X magnification), tablet surface (1000X magnification) was conducted to obtain surface information of these samples by Scanning Electron Microscope SEM-8100FM (Shimadzu, Japan).

DoE factorial statistical study. Two-factor DoE study was designed with 9 batches and a series of experimental works were conducted following the enlisted experimental batches generated at different factor levels of combinations (Table 1) by using Minitab-17 software. Then the responses (DT) were given as input in the software and the software exhibited the statistical outcomes automatically.

\section{RESULTS AND DISCUSSION}

Evaluation of the properties of powder blends. Powder blends had the required properties to be compressed conventionally, as all the test results were within the limit (Table 2). Generally, Carr's index values up to $16 \%$ and values less than 1.25 in terms of Hausner's Ratio are representative indicators for a good to excellent flow properties, while in case of angle of repose 35-40 degrees value represent a good to fair flowability of a powder blend. ${ }^{13,14}$

Evaluation of physical properties of the compressed tablets. The length, width, thickness, weight variation, hardness and friability tests were within the limit and met the compendial acceptance criteria. ${ }^{15-18}$ The physical and mechanical characteristics along with the DT of the compressed tablets of nine batches are given in table 3 .

Fourier transform infrared (FTIR) spectroscopic analysis. FTIR was performed at 1 $\mathrm{cm}^{-1}$ over the region of $4000-500 \mathrm{~cm}^{-1}$. The resultant spectrums of FTIR analysis of different samples are given in figure 1 (A, B, C and D). In FTIR spectrum of Sofosbuvir (Figure 1A) there were evident peaks

Table 2. Pre-compression evaluation of the powder blend.

\begin{tabular}{|c|c|c|c|c|c|}
\hline Batch & $\begin{array}{l}\text { Bulk Density } \\
(\mathrm{gm} / \mathrm{l})\end{array}$ & $\begin{array}{c}\text { Tapped Density } \\
(\mathrm{gm} / \mathrm{l})\end{array}$ & $\begin{array}{l}\text { Hausner's } \\
\text { Ratio }\end{array}$ & $\begin{array}{c}\text { Carr`s Index } \\
(\%)\end{array}$ & $\begin{array}{c}\text { Angle of } \\
\text { Repose (degrees) }\end{array}$ \\
\hline 1 & $0.48 \pm 0.003$ & $0.58 \pm 0.011$ & $1.21 \pm 0.058$ & $20.83 \pm 1.121$ & $38.65 \pm 0.018$ \\
\hline 2 & $0.50 \pm 0.001$ & $0.61 \pm 0.003$ & $1.22 \pm 0.021$ & $20.00 \pm 0.895$ & $37.78 \pm 0.009$ \\
\hline 3 & $0.47 \pm 0.013$ & $0.56 \pm 0.017$ & $1.19 \pm 0.075$ & $19.14 \pm 1.587$ & $37.54 \pm 0.021$ \\
\hline 4 & $0.48 \pm 0.005$ & $0.57 \pm 0.008$ & $1.18 \pm 0.037$ & $18.75 \pm 2.672$ & $39.56 \pm 0.016$ \\
\hline 5 & $0.51 \pm 0.018$ & $0.6 \pm 0.012$ & $1.18 \pm 0.062$ & $17.64 \pm 1.649$ & $35.95 \pm 0.010$ \\
\hline 6 & $0.46 \pm 0.002$ & $0.58 \pm 0.001$ & $1.26 \pm 0.018$ & $19.08 \pm 0.621$ & $39.80 \pm 0.007$ \\
\hline 7 & $0.47 \pm 0.015$ & $0.56 \pm 0.010$ & $1.19 \pm 0.041$ & $19.14 \pm 1.247$ & $39.97 \pm 0.026$ \\
\hline 8 & $0.46 \pm 0.012$ & $0.57 \pm 0.006$ & $1.23 \pm 0.039$ & $19.91 \pm 2.194$ & $38.47 \pm 0.017$ \\
\hline 9 & $0.46 \pm 0.007$ & $0.59 \pm 0.004$ & $1.28 \pm 0.088$ & $21.26 \pm 1.481$ & $37.36 \pm 0.005$ \\
\hline
\end{tabular}

Table 3. Physical characteristics of compressed tablets.

\begin{tabular}{lccccccc}
\hline Batch & $\begin{array}{c}\text { Length } \\
(\mathrm{mm})\end{array}$ & $\begin{array}{c}\text { Width } \\
(\mathrm{mm})\end{array}$ & $\begin{array}{c}\text { Thickness } \\
(\mathrm{mm})\end{array}$ & $\begin{array}{c}\text { Average } \\
\text { weight }(\mathrm{mg})\end{array}$ & $\begin{array}{c}\text { Hardness } \\
\left(\mathrm{kg} / \mathrm{cm}^{2}\right)\end{array}$ & $\begin{array}{c}\text { Friability } \\
(\%)\end{array}$ & $\begin{array}{c}\text { Disintegration } \\
\text { time }(\text { Minutes })\end{array}$ \\
\hline 1 & $18.95 \pm 0.104$ & $9.98 \pm 0.095$ & $4.12 \pm 0.019$ & $808.5 \pm 0.254$ & $6.70 \pm 1.217$ & $0.03 \pm 0.018$ & $3.25 \pm 0.008$ \\
2 & $18.88 \pm 0.051$ & $9.94 \pm 0.048$ & $4.08 \pm 0.008$ & $809.00 \pm 0.127$ & $7.20 \pm 0.087$ & $0.05 \pm 0.002$ & $3 \pm 0.003$ \\
3 & $18.78 \pm 0.155$ & $9.86 \pm 0.351$ & $4.06 \pm 0.010$ & $812.35 \pm 0.549$ & $5.80 \pm 1.391$ & $0.03 \pm 0.041$ & $5.75 \pm 0.013$ \\
4 & $18.76 \pm 0.256$ & $9.84 \pm 0.483$ & $4.04 \pm 0.028$ & $815.55 \pm 2.618$ & $6.40 \pm 1.107$ & $0.08 \pm 0.012$ & $4 \pm 0.007$ \\
5 & $18.94 \pm 0.142$ & $9.80 \pm 0.682$ & $4.10 \pm 0.020$ & $810.60 \pm 1.342$ & $5.50 \pm 0.872$ & $0.07 \pm 0.011$ & $6 \pm 0.021$ \\
6 & $18.86 \pm 0.042$ & $9.82 \pm 0.061$ & $4.04 \pm 0.005$ & $807.56 \pm 0.261$ & $6.60 \pm 0.0349$ & $0.05 \pm 0.005$ & $3 \pm 0.005$ \\
7 & $18.84 \pm 0.351$ & $9.90 \pm 0.537$ & $4.08 \pm 0.017$ & $808.68 \pm 0.847$ & $6.20 \pm 1.821$ & $0.06 \pm 0.019$ & $6.5 \pm 0.015$ \\
8 & $18.56 \pm 0.148$ & $9.92 \pm 0.942$ & $4.08 \pm 0.012$ & $813.30 \pm 1.273$ & $8.00 \pm 1.685$ & $0.05 \pm 0.021$ & $4 \pm 0.017$ \\
9 & $18.76 \pm 0.013$ & $9.86 \pm 0.085$ & $4.04 \pm 0.003$ & $815.30 \pm 1.873$ & $6.80 \pm 1.557$ & $0.07 \pm 0.025$ & $4.25 \pm 0.008$ \\
\hline
\end{tabular}


for Alcoholic Hydroxyl group, Methyl C:H bond, Ester $\mathrm{C}=\mathrm{O}$ bond and Ketone $\mathrm{C}=\mathrm{O}$ bond at 3423.65 $\mathrm{cm}^{-1}, 2924.09 \mathrm{~cm}^{-1}, 1722.43 \mathrm{~cm}^{-1}$ and 1676.14 respectively. There were evident peaks for Alcoholic Hydroxyl group at $3446.72 \mathrm{~cm}^{-1}$ and $3400 \mathrm{~cm}^{-1}$, Amide at $1656.85 \mathrm{~cm}^{-1}$, Aliphatic $\mathrm{N}-\mathrm{H}$ at 3273.20 $\mathrm{cm}^{-1}$ in the FTIR spectrum of Ribavirin (Figure 1B). In the FTIR spectrum of physical mixture of all APIs and excipients (Figure 1C) there were peaks at $3446.79 \mathrm{~cm}^{-1}$ and $3412.06 \mathrm{~cm}^{-1}$ for Alcoholic Hydroxyl group that was present in both Sofosbuvir and Ribavirin, $2920.23 \mathrm{~cm}^{-1}$ for Methylene $\mathrm{CH}$ group which was present in Sofosbuvir, $1718.58 \mathrm{~cm}^{-1}$ for Ester $\mathrm{C}=\mathrm{O}$ bond which was present is Sofosbuvir, $1666.50 \mathrm{~cm}^{-1}$ for Ketone $\mathrm{C}=\mathrm{O}$ which was present in Sofosbuvir and Amide which was present in Ribavirin and $3257.77 \mathrm{~cm}^{-1}$ for Aliphatic N-H that was present in Ribavirin. In the FTIR spectrum of crushed tablet powders (Figure 1D) there were evident peaks at $3446.79 \mathrm{~cm}^{-1}$ and $3408.22 \mathrm{~cm}^{-1}$ for Alcoholic Hydroxyl group that was present in the structure of Sofosbuvir and Ribavirin, $2927.94 \mathrm{~cm}^{-1}$ for Methylene $\mathrm{CH}$ group which was present in Sofosbuvir, $1720.50 \mathrm{~cm}^{-1}$ for Ester $\mathrm{C}=\mathrm{O}$ bond which was present is Sofosbuvir, $1670.35 \mathrm{~cm}^{-1}$ for Ketone $\mathrm{C}=\mathrm{O}$ that was present in Sofosbuvir and Amide which was present Ribavirin and $3255.64 \mathrm{~cm}^{-1}$ for Aliphatic N-H that was present in Ribavirin. So, it was evident that the peaks of different functional groups present in the structure of Sofosbuvir and Ribavirin did not change significantly after mixing or compression, which results in non-interaction between Sofosbuvir and Ribavirin or to the excipients used in the formulations. It represents the stability of the formulations during whole mixing and compression processes and therefore, justifies the combination of Sofosbuvir and Ribavirin formulations with the proposed excipients.

Thermogravimetric analysis (TGA). Thermogravimetric analysis of Sofosbuvir, Ribavirin and Sofosbuvir \& Ribavirin powder mixture are presented in figure 2 (A, B and C). Thermograms of
Sofosbuvir and Ribavirin confirmed the stability up to $207.07{ }^{\circ} \mathrm{C}$ and $201.09{ }^{\circ} \mathrm{C}$ respectively. At the same time Sofosbuvir and Ribavirin powder mixture confirmed the stability up to $198.83{ }^{\circ} \mathrm{C}$. So, both Sofosbuvir and Ribavirin were found heat stable up to about $180{ }^{\circ} \mathrm{C}$ as both individual powder and mixture. As a result, it was safe to handle the drug substances in a higher thermal condition like wet granulation or conventional drying.

X-ray diffraction (XRD) analysis. The characteristic steeper peaks of Sofosbuvir and Ribavirin represent the crystallinity of both drug substances which remained unchanged both in the Sofosbuvir \& Ribavirin powder mixture and in the crushed powder of compressed tablets and thus the stability of the compressed tablets was established (Figure 3).

Scanning Electron Microscopy (SEM) analysis. By performing SEM, the surface morphology was analyzed where figure 4 illustrates that in compressed tablet both bonding and fragmentation took place properly which is necessary to ensure a thoroughly formulated compressed tablet.

Standard curve preparation. Standard curve of Sofosbuvir and Ribavirin in $0.1 \mathrm{~N} \mathrm{HCl}$ are given in figure 5. For Sofosbuvir standard curve, $\mathrm{y}=0.0205 \mathrm{x}+0.0202 ; \quad \mathrm{R}^{2}=0.9988$ and for Ribavirin standard curve, $\mathrm{y}=0.0209 \mathrm{x}+0.0076 ; \mathrm{R}^{2}=0.9965$.

Dissolution studies. The dissolution patterns of Sofosbuvir and Ribavirin in different formulations as of mean values are shown in figures 6 and 7 . Dissolution was measured up to 30 minutes and all batches met the dissolution criteria. ${ }^{19}$ The dissolution profile of batch 2 and batch 6 of Sofosbuvir and batch 1 , batch 2 and batch 6 of Ribavirin showed $100 \%$ dissolution at the specified time period.

Statistical study outcomes. The variables and the responses for consecutive variables are shown in table 4 

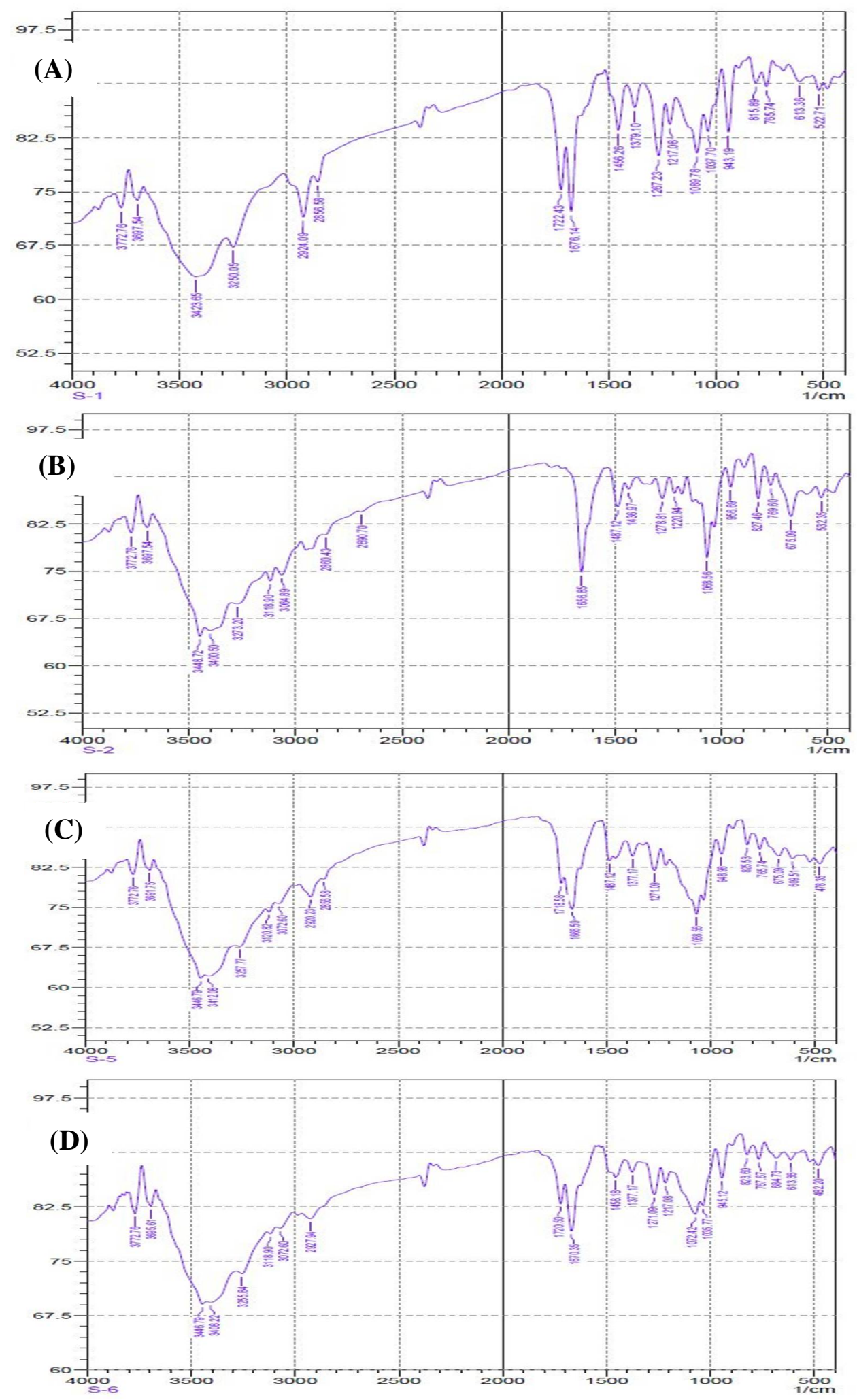

Figure 1. FTIR spectrums of Sofosbuvir (A), Ribavirin (B), physical mixture (C) and crushed tablet powder (D). 

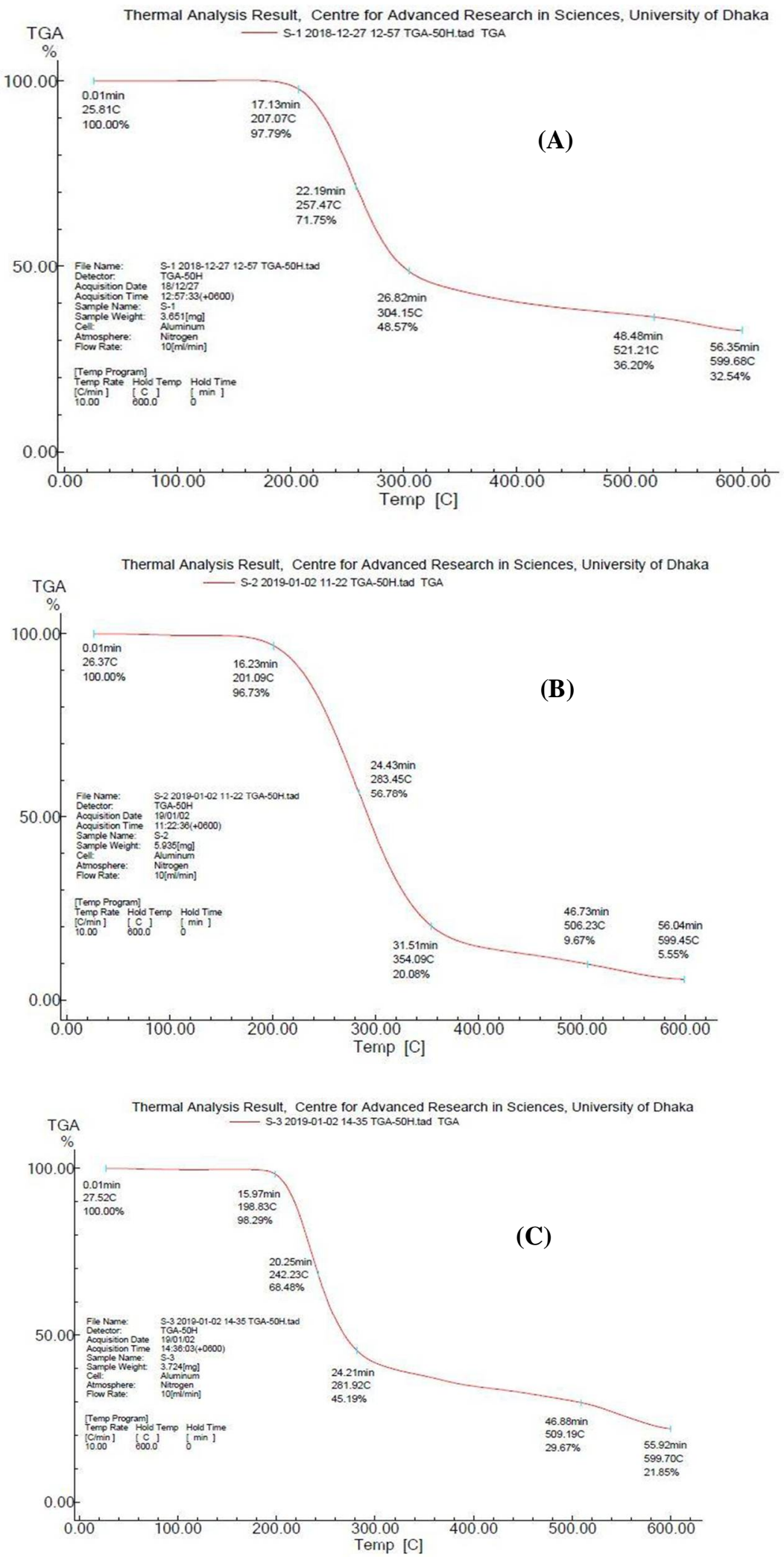

Figure 2. TGA thermograms of Sofosbuvir (A), Ribavirin (B) and Sofosbuvir and Ribavirin powder mixture (C). 

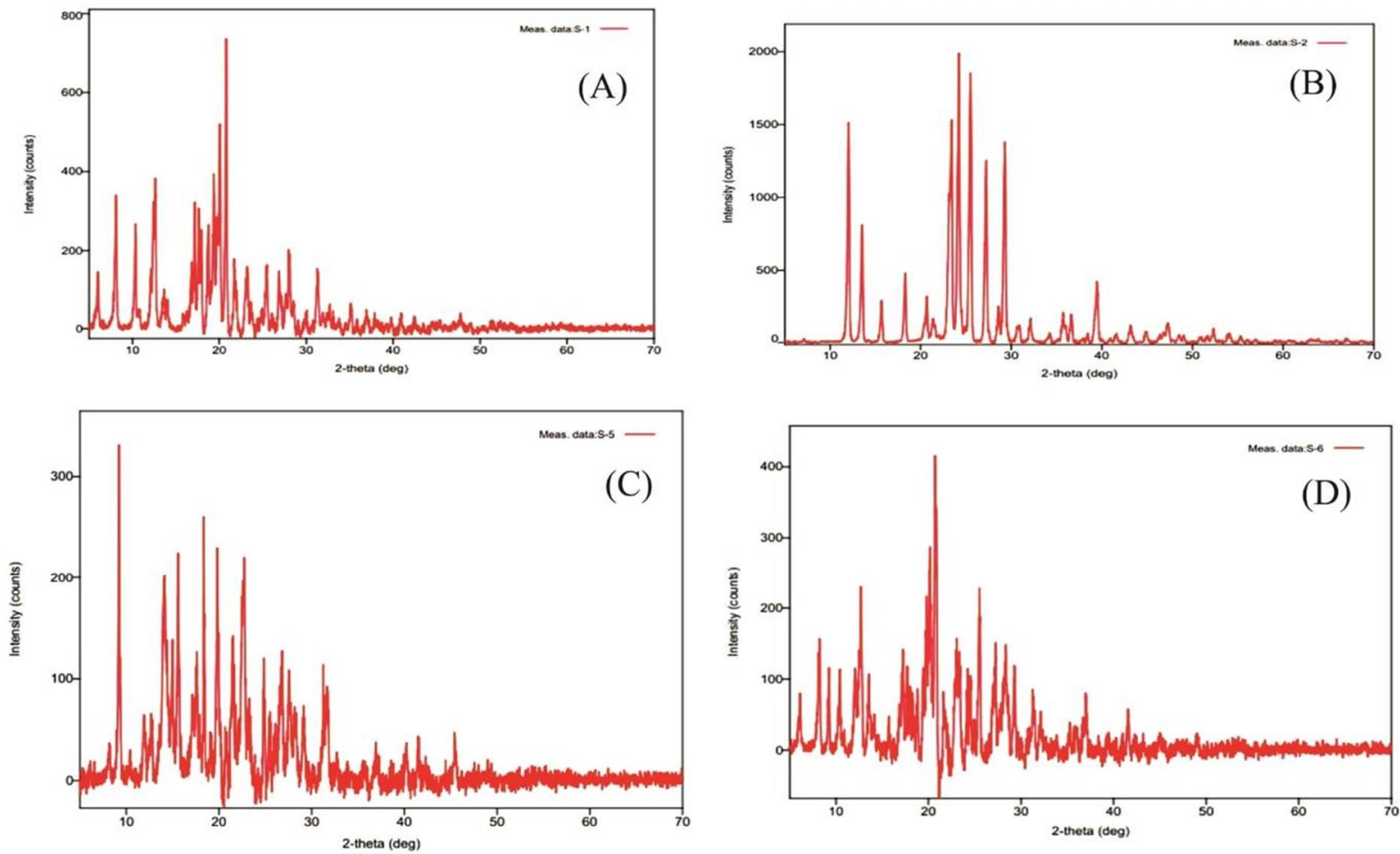

Figure 3. XRD diffractograms of Sofosbuvir (A), Ribavirin (B), Sofosbuvir and Ribavirin powder mixture (C) and crushed tablet powder (D).
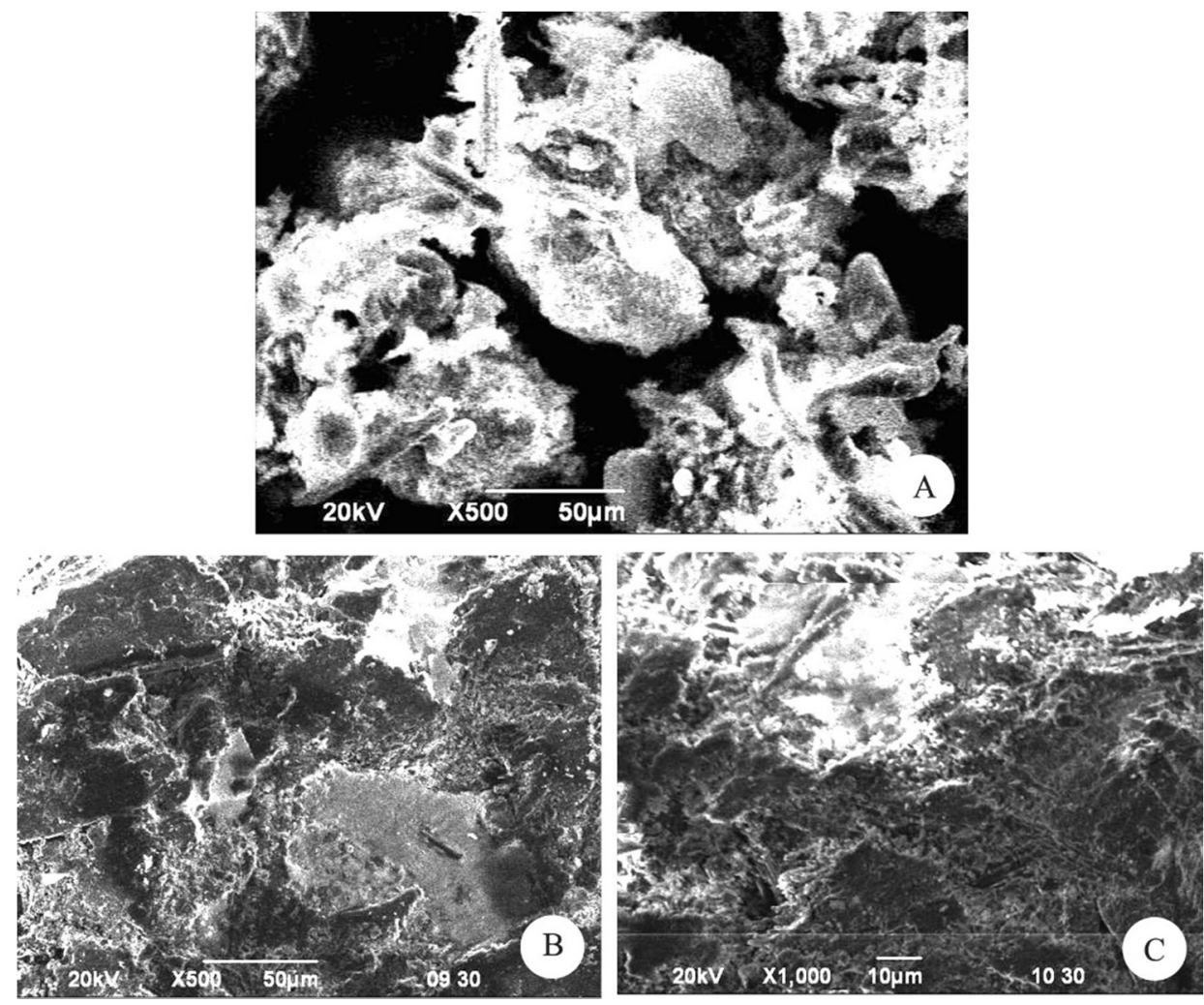

Figure 4. SEM images of (A) physical mixture surface (500X magnification), (B) tablet surface (500X magnification) and (C) tablet surface (1000X magnification). 

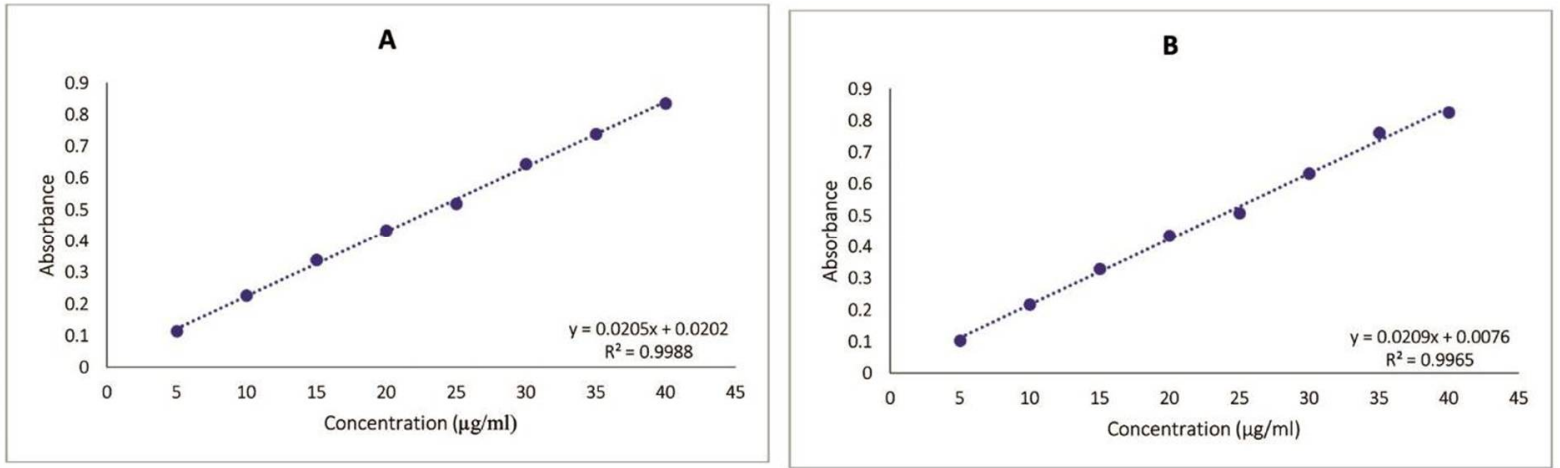

Figure 5. Standard curve of Sofosbuvir (A) and Ribavirin (B) in $0.1 \mathrm{~N} \mathrm{HCl}$.

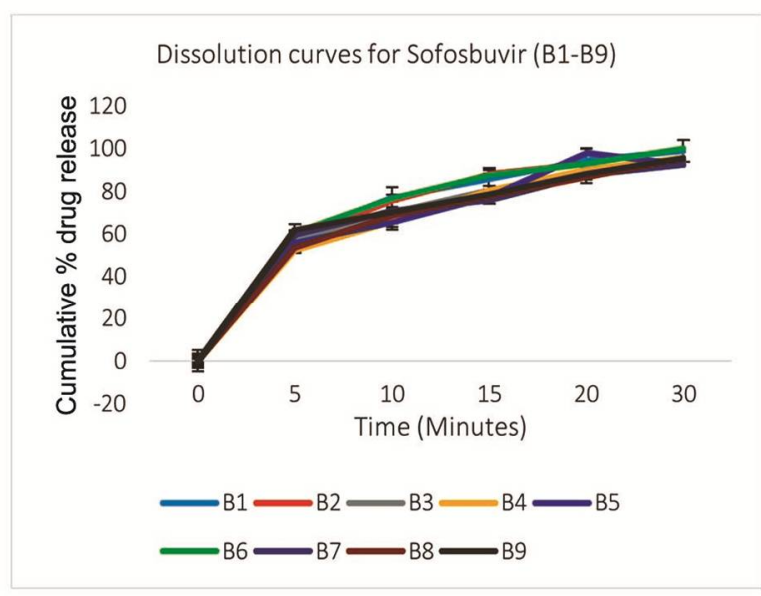

Figure 6. Dissolution curves for Sofosbuvir in different formulations $(n=6)$.

Table 4. The response obtained from the randomized run in a factorial design.

\begin{tabular}{lccc}
\hline \multirow{2}{*}{ uun } & \multicolumn{2}{c}{ Variables } & Response \\
\cline { 2 - 4 } & $\mathrm{X} 1(\%)$ & $\mathrm{X} 2(\%)$ & $\mathrm{Y}(\mathrm{Min})$ \\
\hline 1 & $1.25 \%$ & $2.31 \%$ & 3.25 \\
2 & $2.00 \%$ & $2.00 \%$ & 3 \\
3 & $1.25 \%$ & $0.19 \%$ & 5.75 \\
4 & $2.00 \%$ & $0.50 \%$ & 4 \\
5 & $0.19 \%$ & $1.25 \%$ & 6 \\
6 & $2.31 \%$ & $1.25 \%$ & 3 \\
7 & $0.50 \%$ & $0.50 \%$ & 6.5 \\
8 & $1.25 \%$ & $1.25 \%$ & 4 \\
9 & $0.50 \%$ & $2.00 \%$ & 4.25 \\
\hline
\end{tabular}

The ANOVA test results for the response are shown in table 5. From the ANOVA, F-value of the model was 96.66 and this implied the model's

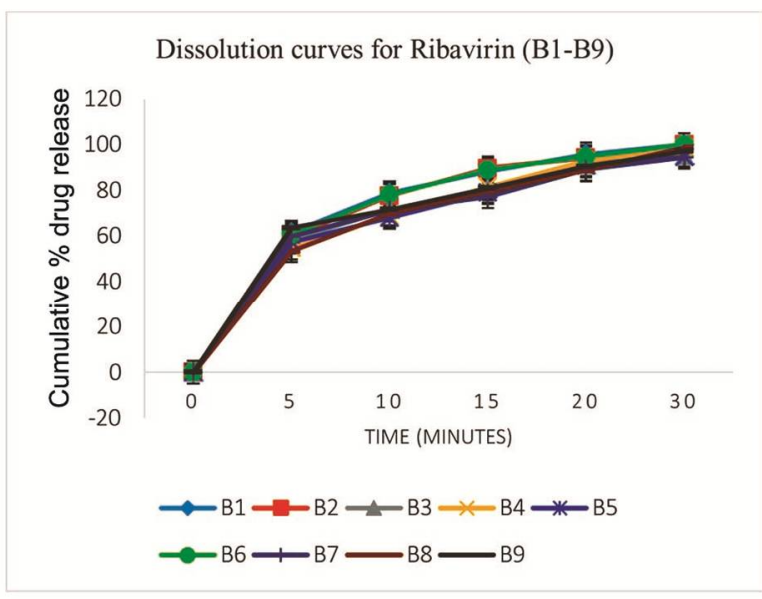

Figure 7. Dissolution curves for Ribavirin in different formulations $(n=6)$.

significance. Here, CCS, PK30 and CCS*PK30 were also found significant $(\mathrm{P}<0.05)$. Here for all factors, the P-values were below 0.05, which represented the significance of all data. Moreover, the P-value for lack-of-feat was 1.642, which is greater than 0.05 . So, the chance of error during the test was not significant which means there was no chance of error during the proposed process and analysis. Regression equation in Uncoded Units is given below:

$\mathrm{DT}=8.364-2.027 \mathrm{CCS}-1.825 \mathrm{PK} 30$ +0.556 CCS*PK30

The equation can be used to predict the reaction for the given magnitude of each factor. Here, the levels must be stated in the original units for each factor. 
Table 5. ANOVA test for the response.

\begin{tabular}{lcccc}
\hline Source & DF & F-value & P-value & Comment \\
\hline Model & 3 & 96.66 & 0.0006 & Significant \\
Linear & 2 & 140.99 & $<0.0001$ & Significant \\
CCS & 1 & 163.87 & $<0.0001$ & Significant \\
PK30 & 1 & 118.11 & $<0.0001$ & Significant \\
2-way Interactions & 1 & 8.02 & 0.037 & Significant \\
CCS*PK30 & 1 & 8.02 & 0.037 & Significant \\
Lack-of-feat & 1 & 1.624 & 1.642 & Not Significant \\
\hline
\end{tabular}

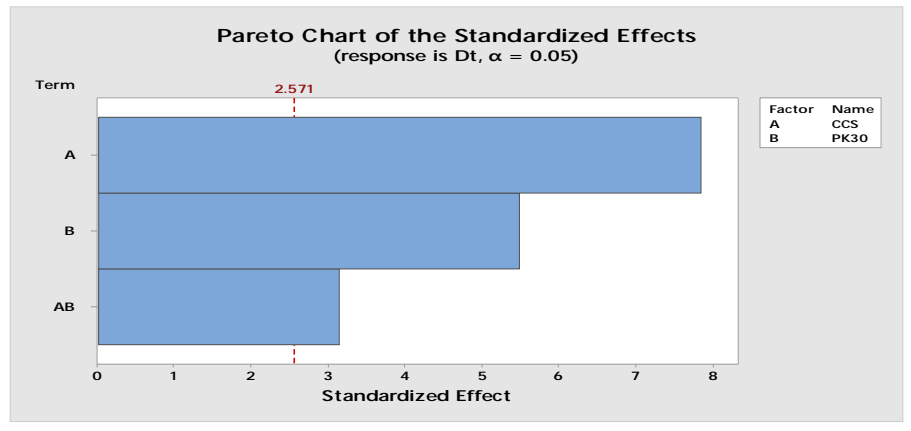

Figure 8. Pareto chart of standardized effects of the formulation factors.

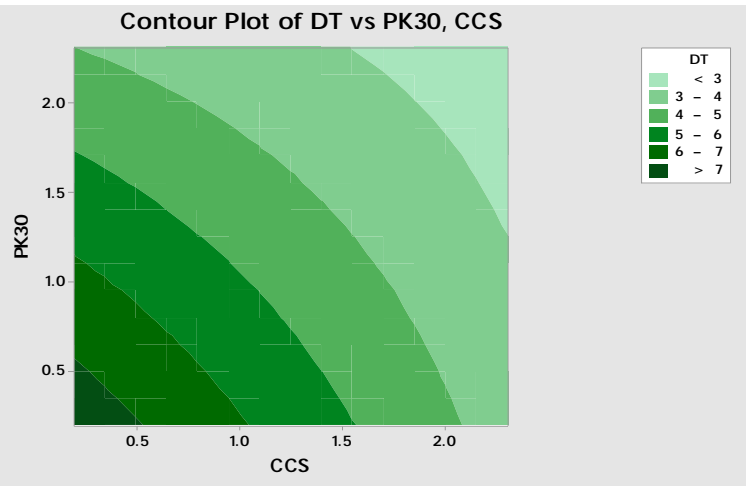

Figure 9. Contour plot of DT vs PK30 and CCS.

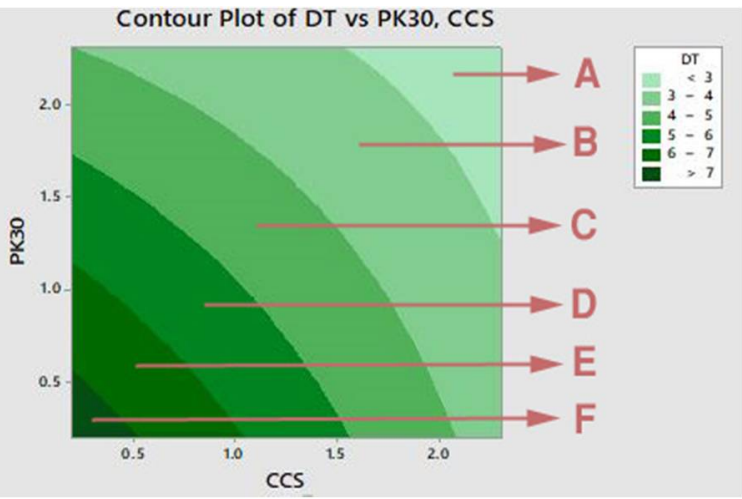

Figure 10. Contour plot of DT vs PK30 and CCS (Labeled). 
In the Pareto diagram from figure 8 , it was apparent that the model was significant for all A, B and $\mathrm{AB}$ factors. Here, $\mathrm{A}$ signifies $\mathrm{CCS}$ and $\mathrm{B}$ signifies PK30 and $A B$ signifies the use of both CCS and PK30. From the Pareto chart, we can interpret the significance of all three models.

From the contour plot, we can predict the response for different values of variables. For this study, the response was DT and the variables were concentrations of PK30 and CCS. In the Contour plot in figure 9, the different ranges of dissolution time are colored in different intensity. The range of the concentrations of Croscarmellose Sodium and Povidone K30 can be predicted for desired dissolution time from the plot. For example: if we need DT below 3 minutes, 3-4 minutes, 4-5 minutes, 5-6 minutes, 6-7 minutes and more than 7 minutes then the concentration of CCS and PK30 should be in range $\mathrm{A}, \mathrm{B}, \mathrm{C}, \mathrm{D}, \mathrm{E}$ and $\mathrm{F}$ respectably of figure 10.
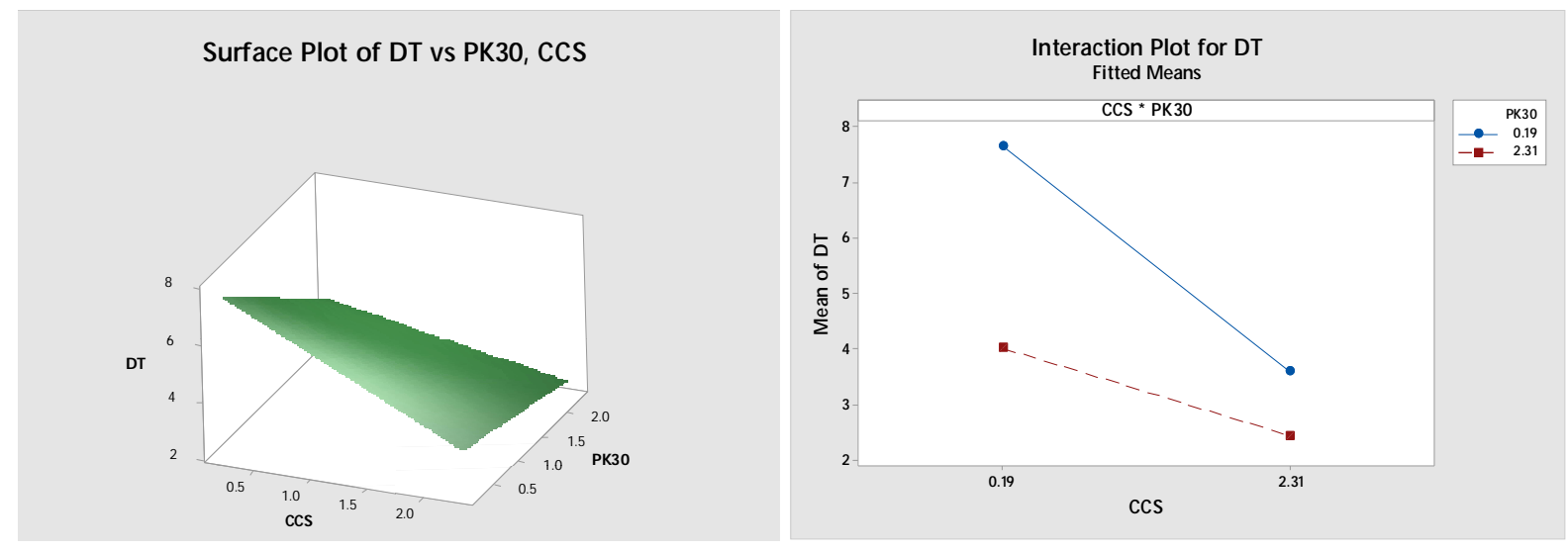

Figure 11. Surface plot of DT vs PK30 and CCS (Left); Interaction plot for DT (Right).

From the interaction plot of DT in figure 11, we can predict the relationship between the two factors CCS and PK30. While keeping PK30 constant at $0.19 \%$, the change of DT with the change of CCS is shown by the blue line. And while keeping PK30 constant at $2.31 \%$, the change of DT with the change of CCS is shown by the red line. Figure 7 revealed that if we use PK30 in a higher concentration, the lower DT will be found by using the same amount of CCS. Therefore, both CCS and PK30 have a synergistic effect on DT.

\section{CONCLUSION}

For the treatment of Hepatitis $\mathrm{C}$ virus infection, a holistic medication containing Sofosbuvir and Ribavirin will be very much helpful to decline the mortality rate. Considering this, in our research work a new tablet dosage form containing Sofosbuvir and Ribavirin was developed and evaluated. From the
DoE analysis, we found that the study was statistically significant. It was safe to use Sofosbuvir and Ribavirin in the same tablet dosage form with excipients used in the study. From this research study, we could propose a novel tablet dosage form containing Sofosbuvir and Ribavirin for a better and more patient compliant $\mathrm{HCV}$ infection treatment though there is scope for further studies.

\section{CONFLICT OF INTEREST}

The authors declare no conflicts of interest.

\section{ACKNOWLEDGEMENTS}

The authors are grateful to Incepta Pharmaceuticals Limited for providing Sofosbuvir and Ribavirin and also to the Centre for Advanced Research in Sciences (CARS), University of Dhaka for providing laboratory support. 


\section{REFERENCES}

1. Scheel, T.K. and Rice, C.M. 2013. Understanding the hepatitis $\mathrm{C}$ virus life cycle paves the way for highly effective therapies. Nat. Med. 19, 837-849.

2. Lavanchy, D. 2009. The global burden of hepatitis C. Liver Int. 29, 74-81.

3. Lavanchy, D. 2011. Evolving epidemiology of hepatitis C virus. Clin. Microbiol. Infect. 17, 107-115.

4. Lanini, S., Easterbrook, P.J., Zumla, A. and Ippolito, G. 2016. Hepatitis C: global epidemiology and strategies for control. Clin. Microbiol. 22, 833-838.

5. Wang, L.S., D'Souza, L.S. and Jacobson, I.M. 2016. Hepatitis C-A clinical review. J. Med. Virol. 88, 1844-1855.

6. Martin, P. and Jensen, D.M. 2008. Ribavirin in the treatment of chronic hepatitis C. J. Gastroenterol. Hepatol. 23, 844-855.

7. Abonyi, M.E. and Lakatos, P.L. 2005. Ribavirin in the treatment of hepatitis C. Anticancer Res. 25, 1315-1320.

8. Abraham, G.M. and Spooner, L.M. 2014. Sofosbuvir in the treatment of chronic hepatitis C: new dog, new tricks. Clin. Infect. Dis. 59, 411-415.

9. Pubchem. 2018. Compound Summary: Sofosbuvir. National Institute of Health, USA. This article was retrieved from https://pubchem.ncbi.nlm.nih.gov/compound/psi-7977.
10. Pubchem. 2018. Compound Summary: Ribavirin. National Institute of Health, USA. This article was retrieved from https://pubchem.ncbi.nlm.nih.gov/compound/37542.

11. Fukuda, I.M., Pinto, C.F.F., Moreira, C.S., Saviano, A.M. and Lourenço, F.R. 2018. Design of Experiments (DoE) applied to Pharmaceutical and Analytical Quality by Design (QbD). Braz. J. Pharm. Sci. 54, 001-006.

12. Bhutani, H., Kurmi, M., Singh, S., Beg, S. and Singh, B. 2014. Quality by design (QbD) in analytical sciences: an overview. Pharma Times. 46, 71-75.

13. Bulk Density and Tapped Density of Powders. 2014. The United States Pharmacopeial Convention (Section 616), USA.

14. Powder Flow. 2011. The United States Pharmacopeia ( $35^{\text {th }}$ edition, Section 1174), USA.

15. Tablet Breaking Force. 2011. The United States Pharmacopeia ( $35^{\text {th }}$ edition, Section 1217), USA.

16. Tablet Friability. 2011. The United States Pharmacopeia $\left(35^{\text {th }}\right.$ edition, Section 1216), USA.

17. Uniformity of Dosage Units. 2011. The United States Pharmacopeia ( $35^{\text {th }}$ edition, Section 905), USA.

18. Disintegration. 2011. The United States Pharmacopeia $\left(35^{\text {th }}\right.$ edition, Section 701), USA.

19. Dissolution. 2011. The United States Pharmacopeia ( $35^{\text {th }}$ edition, Section 711), USA. 